\title{
Arthur Omar, Congo e o antidocumentário: mediações e crise na representação
}

\author{
Gilberto Alexandre Sobrinho*
}

Resumo: O artigo estuda o pensamento e a realização em documentário do artista brasileiro Arthur Omar. Parto de uma análise de seu texto "O antidocumentário provisoriamente" e analiso, em seguida, o filme Congo, um documentário elaborado a partir de um tema caro aos estudos antropológicos, a congada, mas que se realiza por um processo de experimentação profunda.

Palavras-chave: Arthur Omar; documentário brasileiro; antidocumentário; Congo.

Resumen: Estudio del pensamiento y de la realización en el documental del artista brasileño Arthur Omar. Parto de un análisis de su texto $\mathrm{O}$ "antidocumentário provisoriamente" para analizar, a continuación, la película Congo, un documental que se elabora a partir de un tema caro a los estudios antropológicos, la congada, pero que se realiza mediante un profundo proceso de experimentación profunda.

Palabras clave: Arthur Omar; documental brasileño; antidocumental; Congo.

\begin{abstract}
This is a reflection about the thoughts and documentary filmmaking by Brazilian artist Arthur Omar. I start by analyzing his text called " $\mathrm{O}$ antidocumentario provisoriamente" and, then, an analysis of the film Congo is developed. It is a documentary about a theme that has interested anthropological studies, the "congada", a Brazilian cultural popular expression. The result is a deep artistic experimentation. Keywords: Arthur Omar ; Brazilian documentary; antidocumentário; Congo.
\end{abstract}

Résumé: Dans cet article j'étudie la pensée et la réalisation documentaire de l'artiste brésilien Arthur Omar. Il s'agit d'une analyse de son texte $O$ antidocumentário provisoriamente, suivie d'une analyse du film Congo, un documentaire en cours de préparation à partir d'un thème cher aux études anthropologiques, la congada, mais qui se réalise à travers un profond processus d'expérimentation. Mots-clés: Arthur Omar; documentaire brésilien; antidocumentaire; Congo.

\footnotetext{
* Universidade Estadual de Campinas - UNICAMP, Instituto de Artes, Departamento de Multimeios, Mídia e Comunicação. 13010050, Campinas, Brasil. E-mail: gilsobrinho@iar.unicamp.br

Submissão do artigo: 31 de dezembro de 2015. Notificação de aceitação: 09 de fevereiro de 2016.
}

Doc On-line, n. 19, março de 2016, www.doc.ubi.pt, pp. 124-135. 
De uma certa forma, rompi com Congo. Para o mal.

Arthur Omar

Este texto toma como objeto parte da obra do artista multimídia Arthur Omar, que constrói seu trabalho pela profusão de gêneros e de linguagens (cinema, vídeo, fotografia, instalações, música, poesia, literatura e desenho) e que transita por universos temáticos os mais variados. Tratarei especificamente sobre sua incursão no domínio do documentário, partindo de uma análise de seu texto $O$ antidocumentário provisoriamente (Omar, 1999) e analisando seu filme Congo (1972), sendo um documentário elaborado a partir de um tema caro aos estudos das ciências sociais e da cultura popular, a congada, e que se realiza por um processo de experimentação profunda.

O filme não obedece aos esquemas canônicos de apresentação do fenômeno retratado e se enuncia como um filme em branco, em que a maior parte dos planos é composta de letreiros pretos sobre fundo branco que intercalam com imagens captadas de pessoas, lugares e animais. Não há narração no sentido tradicional e tampouco a fala dos personagens, apenas sons de tambores que se mesclam a uma música erudita e uma voz over que desconstrói o didatismo do gênero.

Na obra de Arthur Omar tem-se um rico trânsito de signos e um olhar investigativo que opera, por via da experimentação, sobre os limites das linguagens em sua capacidade de apreender o universo cultural, transbordando em perguntas e respostas que revêem a tradição artística e interrogam sobre o saber epistemológico.

Fluxos intermináveis em torno da cultura e da experimentação: introdução à obra de Arthur Omar

A aparição de Arthur Omar no contexto artístico brasileiro se deu na década de setenta, período marcado pela forte repressão política, durante a Ditadura Civil-Militar e pela continuidade do vigor criativo que acometia a arte fortemente desde a década de 1960 (Xavier, 2012). Cinema Novo, Tropicalismo e Cinema Marginal seriam, assim, marcos antecessores que poderiam, de formas variadas ter influenciado seu período de formação.

Sua obra carrega traços instigantes. De imediato, nota-se a criação de um universo extremamente particular, do primeiro filme Sumidades Carnavalescas (1971), às mais recentes realizações, como a instalação Fluxos, a série de fotografias $O$ esplendor dos contrários, ambas de 2001, ou a exposição Zo- 
oprismas (2006), o artista transita entre suportes e linguagens, e nisto reside uma postura atenta para os vários meios que a arte contemporânea se utiliza para construir imagens, para dialogar com a palavra escrita e para captar os fluxos e irradiações poéticas dos sons. Não há um traço distintivo único, em sua atitude artística encontra-se o carnaval, a história do Brasil, personagens do universo policial, a natureza e o homem da Amazônia, manifestações da cultura popular, a periferia da metrópole, a moda, os artistas com que convive, sua casa, um gato, a luz.

Artista da paisagem urbana e rural, do rosto, do corpo, da colagem e da memória, Omar exalta, sobretudo em seus trabalhos visuais, a dimensão plástica, em que interessam mais as potencialidades da composição, que ele capta, modela e restitui a sua maneira. A memória atua como expediente capaz de conferir grande dosagem reflexiva, pois não se trata de uma obra alheia ao contexto em que surge, seu pronunciamento estético e político é forte e declarado, a exemplo de seu clássico Triste trópico (1974), filme marcado pela colagem de materiais e pelo viés antropofágico tão caro à arte brasileira e a nossa dimensão cultural e, pode-se dizer também que há algo no filme que o conecta ao espírito tropicalista de anos anteriores. Arthur Omar é um construtor e um tradutor de imagens místicas, míticas, profanas, engajadas, abstratas, sensuais e desconcertantes. Imagens imantadas de radicalidade e de experimentação em torno da natureza e da cultura.

É assim o filme Tesouro da juventude (1977), elaborado a partir de colagens de imagens de filmes de cavação e de filmes de George Méliès. Neste trabalho, o artista se torna arqueólogo e recria um passado distante cravado na memória de um cinéfilo. O filme é uma homenagem a Alberto Cavalcanti e ao seu filme En rade e se estrutura a partir da herança vanguardista dos filmes do começo do século XX. A música orquestrada cede para uma voz over que surge para aumentar o clima de estranheza. Em uma declaração, quase ao final, encontramos a chave do mistério que perpassa plano a plano, servindo como espécie de revelação, assim, ouvimos "Onde começa o desejo? O desejo não tem começo", eis o mistério, o desejo é o que move a atividade criadora, fonte labiríntica para os desvios da criação. Dos achados arqueológicos está a imagem de um homem negro, uma coletividade que alude ao oriente mulçumano, imagens do cineasta-mágico George Méliès, rochas, céu, aves, mar. Filme que transborda em texturas, amalgamadas por uma estrutura labiríntica, em que não há um fio condutor, sem referências de tempo e de espaço, é uma incursão experimental ao princípio da mediação entre a câmera e o mundo.

Outro exemplo forte de investigação da potência da imagem é o filme Ressurreição (1989), são imagens de fotografias tiradas de jornais populares e de 
arquivos explorando a violência em que prevalece o uso da montagem, tendo uma música religiosa ao fundo. Omar investiga nas imagens da violência a desagregação do corpo, a alma perdida, a condição humana em seu estado de putrefação e de fetiche, mas isso só se realiza mediante a montagem, artefato cinematográfico que permite a fruição temporal e espacial da encenação da dor e do espetáculo, imprimidos pelo ritmo de planos de curta duração e da aproximação da lente diante do horror. Há toda uma elaboração artística que visa, em última instância, provocar uma ascese no espectador, direcionar seus sentidos para um estado de contemplação conflitiva.

No território do vídeo, ainda num momento em que as texturas da imagem em movimento podiam ser singularizadas, antes de a convergência digital fazer desaparecer essas fronteiras que eram mais ou menos visíveis, também verificamos esse trabalho de incursão pelas potências do meio, naquilo que o suporte permitia para a atividade criadora. Na trilogia A última sereia (1997), Pânico sutil (1998) e A lógica do êxtase (1998), filmes feitos para o Estúdio M.Officer, Omar promove interfaces entre a estética do vídeo e a performance, há nessa trilogia um misto de teatro, vídeo, pintura, escultura, sendo todos os signos erigidos e encadeados em nome da passarela, signo maior do universo da moda. Assim, opera-se um trabalho meticuloso com o tempo de fabricação da imagem, fusões no interior do plano, busca pela abstração na imagem figurativa.

Ao lado dessa postura investigativa e experimental, atestada principalmente em sua produção audiovisual, encontramos na obra de Arthur Omar o diálogo com gêneros tradicionais no território da fotografia e do vídeo documentário. Nessa ordem, o ensaio fotográfico Antropologia da face gloriosa (1997) é uma revisitação do retrato concebido a partir da captura de estados "gloriosos" de faces mascaradas, maquiadas ou nuas, extraídas de um único clique a partir dos festejos do carnaval carioca. A série, apresentada em quatro versões ${ }^{1}$ e editada em livro, restitui via palavra e imagem toda uma atmosfera mítica que se instala nos corpos durante o carnaval, não se trata de um documento realista sobre as emanações que acometem sujeitos variados durante a festa, mas uma intervenção necessária mediante o clique e, posteriormente, na revelação, para que aspectos culturais dos ritos possam ser redimensionados em uma tradução verbo-visual de um momento que acontece pela ativação dos cinco sentidos. Essa emanação do êxtase em imagens do carnaval é um traço que se prolonga na obra do artista e se vincula a um propósito centrado na cri-

1. As exposições foram realizadas da seguinte forma: Antropologia da face gloriosa I, 1984, exposição individual no Mam, Rio de Janeiro; Antropologia da face gloriosa II, 1993, Mis, São Paulo; A grande muralha, 1997, 24ª Bienal de São Paulo. 
ação que se engendra a partir de elementos ritualísticos que compõem nosso legado cultural.

No limite entre a ousadia e a tradição está A coroação de uma rainha (1993), filme documentário realizado em vídeo, em que Omar capta a cerimônia de Coroação da Rainha Alzira, de 65 anos, moradora de Jatobá, próximo a Belo Horizonte. Povoado por um intenso clima de magia, em que imagens da natureza, da festa e de seus participantes são captados por uma câmera desautomatizada e sublime. O filme traduz por um olhar antropológico os movimentos do cerimonial que conjuga festa e religião, tratando-se de um espetáculo que se conforma a outros tantos festejos da cultura popular brasileira. Nessa obra, destaca-se a incidência de uma antropologia que atravessa a produção de Omar, bem como uma recusa com a experimentação em seu sentido mais radical, o que culmina num filme quase didático, vinculado a uma certa tradição do documentário, com nuanças poéticas.

Artista polimorfo por excelência, Arthur Omar instiga a percorrer sua obra em busca de respostas. Seus filmes, objetos destacados nessa introdução, concentram um universo de tensões que se vinculam imediatamente ao percurso da experimentação, cujos marcos remontam à idéia de vanguarda. Para uma apreciação mais centrada de sua produção, analisaremos o filme Congo (1972), tendo em vista ser um filme que por si só problematiza o formato documentário, traz em sua organização todo um pronunciamento radical sobre o tema que se propõe a enunciar, filia-se ao viés antropológico, elemento que se estende em outros filmes do diretor.

\section{Um filme em branco ou o filme em crise: as mediações em Congo}

Não existe uma problemática única que cerca o formato documentário. Desde suas origens, vemos transcorrer posturas diversas no tratamento dado aos temas que se enunciam sob a etiqueta do filme documentário, fazendo eclodir, sob o ponto de vista teórico, diversas discussões sobre sua especificidade, e sob o ponto de vista da realização, variações no que tange a tomada de decisões sobre o que filmar e, principalmente, como filmar os eventos tidos como objetos do documentário.

No ensaio intitulado $O$ antidocumentário provisoriamente, ${ }^{2}$ Arthur Omar imbui-se da tarefa de traçar um diagnóstico sobre o documentário, problematizando suas fronteiras e estabelecendo uma crítica à produção convencional, bem como àquela elaborada pela vanguarda. Sua atitude tem como princípio

2. Texto de Arthur Omar publicado em 1972, no Caderno Comunicação do Jornal do Brasil, em seguida foi publicado na revista Vozes, n.06, ano 72, 1978 e reeditado em Cinemais, n.08, novembro/dezembro 1997 (utilizaremos essa última edição neste artigo). 
rever os processos pelos quais o filme documentário se assenta e a partir daí lançar as bases para o que ele define como antidocumentário, tendo o filme Congo como proposta radical desse pensamento.

Em tom de manifesto, o texto parte de uma análise da maneira como o documentário se firmou na seara cinematográfica, mantendo em sua elaboração formal os mesmos procedimentos do filme de ficção, sendo ambos assentados na função de espetáculo. Deste modo, o documentário perde sua autonomia e o conteúdo do filme passa a ser consumido tal qual se procede diante de um filme fictício. É contra esse cenário que Omar se pronuncia:

A atitude documental é uma atitude entre outras atividades possíveis no tratamento de um tema. Este texto procura justamente levantar o problema de que novas atitudes talvez sejam mais produtivas hoje no Brasil do que simplesmente partir para o filme documentário generalizado sobre as nossas coisas e a nossa cultura, numa atitude de conservação e preservação que, na verdade, nada conserva e nada preserva, esquecendo que o fundamental é o filme como gesto e ação, uma obra aqui e agora, com sua forma aqui e agora, o resultado concreto de uma decisão de filmar e dar forma a uma obra concreta, e não a repetição mecânica e infinita de conteúdos que estão do outro lado da linha, linha essa que sempre existirá enquanto persistir a atitude documental, a de mero repórter, sem formulação de um projeto de absorção real das lições do objeto no corpo imediato da obra e, em seguida, no setor em que essa obra vai circular. Em suma, sem um novo Método. (p.183)

Se a vanguarda experimental funciona tradicionalmente como contraponto ao cinema clássico, aos olhos de Omar o que se realiza é justamente o contrário, pois ao se articular por um conjunto de negações, o que se estabelece é novamente a afirmação do gênero dominante. Contra a atitude vazia de certa vanguarda e em nome de um documentário que possa dialogar profundamente com os temas a que se propõe, o autor propõe o que denomina antidocumentários.

Omar segue a reflexão e de antemão destaca no filme Congo certos elementos que respondem à problemática do filme documentário que só pode ser discutida no contexto da cultura brasileira. Sua noção de documentário prevê a exterioridade do sujeito e do objeto ["Uma coisa é participar da congada, outra é estudá-la. O documentário é isso: estudar a congada” (p.189)], revisão do papel do espectador, posicionamento do documentário dentro da cultura, visão da cultura brasileira como processo e movimento, detecção de uma pergunta no ar, sendo esse último aspecto bastante determinante:

Então, perguntar como pode o cinema documentar a cultura brasileira é perguntar como vai ser a cultura brasileira. Porque esses filmes, do modo como forem feitos, e seus resultados, entrarão dentro do círculo da cultura e comporão realidade do seu setor cinema. Numa cultura nova como a nossa, em que a questão, a pergunta no ar, a pergunta dominante é a da construção dessa 
cultura, a sua fisionomia futura, pensar a forma do documentário é uma coisa de muita responsabilidade porque se estará decidindo sobre os limites específicos com que certos aspectos culturais vão ser reelaborados e encarados e consumidos dentro dessa cultura; além disso, outro problema, se estará decidindo da forma dos filmes que vão compor essa cultura. (p.200).

O que se pode notar é que seu posicionamento diante do documentário se vincula a um propósito centrado na inserção do produto cultural, o filme, na cultura em que ele emerge e tenta sobreviver. Há, declaradamente, um posicionamento político, uma tomada de decisões que não abandona o processo histórico em nome expressão artística. Esta só pode ser entendida plenamente em sua obra como fruto de uma postura que visa questionar os limites da arte na medida em que essa exigência for detectada no próprio contexto em que é produzida, pelo menos é o que indica o texto e a provocação que é o filme Congo.

O assunto do filme é a congada, definida por Câmara Cascudo como:

(...) autos populares brasileiros, de motivação africana, representados no Norte, Centro e Sul do país. Os elementos de formação foram: a) coroação dos Reis de Congo; b) préstitos e embaixadas; c) reminiscências de bailados e guerreiros, documentativos de lutas, e a reminiscência da Rainha Njinga Nbandi, Rainha de Angola, falecida a 17 de dezembro de 1663, a famosa Rainha Ginga, defensora da autonomia do seu reinado contra os portugueses, batendo-se constantemente com os soldados vizinhos, inclusive o de Cariongo, circunscrição de Luanda. (Cascudo, 1979: 242-243).

Para Artur Ramos, estas danças de Congos "são evidente sobrevivência histórica de antigas epopéias angola-congolenses, com as suas cerimônias de coroação de monarcas, lutas destas monarquias umas com as outras e contra o português invasor e episódios vários". ${ }^{3}$

Nos onze minutos do filme não presenciamos a congada, em nenhum instante é oferecida qualquer imagem que faça remissão direta a essa manifestação, como se verifica tradicionalmente nos documentários sobre esse tipo de assunto. Em seus próprios termos, Omar não se propõe a "uma nova visão da congada, o Congo, objetivamente, não é o tema do filme, o tema é a tensão entre o conhecimento erudito e uma prática popular que está colocada em outro nível de realidade e que em última instância não se comunica" (Ramos, 1993). O filme traduz o universo da congada indiretamente, aposta na capacidade interpretativa do espectador em captar a visão particular do cineasta sobre o fenômeno, apresentado de maneira emblemática planos constituídos, em sua maioria, de signos verbais, imagens que escapam a uma referencialidade explícita, sons de tambores, música erudita e uma voz over de uma criança, o

3. Apud Cabral, O.R. (1951). As danças de congos no sul do Brasil. Província de São Pedro, jun., 06(15): 102-105. Porto Alegre. 
momento mais plausível do filme, que lê trechos da versão de Mário de Andrade sobre a manifestação da congada.

Logo após os créditos iniciais, surge um plano onde se lê "um filme em branco" e em seguida, surgem alternadamente planos em branco e em negro e somos levados a decifrar uma série de microtextos (frases ou palavras) que evocam um posicionamento do cineasta perante o fenômeno. Trata-se de um exercício de apreensão que busca desconstruir, principalmente, por via da palavra a congada, assimilando suas características principais e inserindo-a numa reflexão histórica e social. Assim, um plano enuncia "material negro contra material branco", em outro momento surge "instrumentos africanos contra desintegração das figuras" ou "forma superior de cultura contra instituição teatral popular" e outros que se articulam mediante oposições ou junções do tipo "carne + razão", "coisas naturais + coisas didáticas" ou "1618 + 1972" e revelam um olhar em que a restituição cede para um processo de síntese e de interrogação sobre a inserção do fenômeno no processo histórico em que ele nasce e sobrevive, e isso se realiza pela evocação de seus princípios e características que se articulam de maneira provocativa, pois se trata de algo que evoca a violência e a resistência da diáspora africana, daí a voz inquiridora do cineasta que não deixa de apontar para as contradições advindas do processo de opressão, do embate entre o negro e o branco e a heterodoxia que marca o Congo. Branco e negro enformam o filme, assumem feições distintas, misturam-se. Mas há uma recusa em se fixar na dialética da cultura e não apresentar uma forma documentária não menos conflitiva, daí a expressão "filme em branco", em que a materialidade do celulóide, as regras do gênero, os meios e instrumentos passam por processos de revisão.

Tratando-se de um filme que pode ser lido, visto e ouvido, sua enunciação polifônica, pontuada por recortes variados, instaura um objeto de várias faces. A noção de unidade discursiva, fundada na lógica espaço-temporal não ganha voz em seu corpo textual. Como filme documentário, verifica-se, de antemão, a crise do sujeito e a desagregação de um pronunciamento totalizante que possa explicar didaticamente o tema exposto. Ao optar por intrincada trama enunciativa, verificamos a existência de mediações ${ }^{4}$ atualizadas na imagem e no som que expõem a crise do conhecimento livresco e do discurso das ciências humanas, em especial o discurso antropológico, bem como o questionamento da representação no documentário influenciado, sob o ponto de vista do conteúdo, pelas ciências sociais, e sob o ponto de vista da linguagem, pelo cinema clássico.

4. Tomamos o termo apresentado por Renov: "a mediação refere-se àqueles atos de intercessão, reconciliação ou interpretação intrínseco a todos fenômenos sociais”. (Renov, 1986: 72). 
A mediação pela escrita é um gesto provocativo que nega o preceito baziniano de preservação e restituição do mundo pela câmera cinematográfica. Sendo a maioria dos planos compostos por signos verbais, alude-se a um gesto irônico em que o realizador explicita não só seu saber livresco, mas qualquer outra abordagem "científica" que tenta, de forma centralizadora, catalogar, informar, interpretar, registrar eventos da cultura. Quanto a esse aspecto, Bernardet (1985: 96) assume o seguinte ponto de vista, tratando do filme em questão: "Queremos acreditar que o saber científico é uma ponta para o real, nos fala dele, o interpreta, o expressa, ao limite é o próprio real. A partir do momento em que este saber fica cortado do objeto em função do qual teria sido construído e que o justifica, ele fica sem função”. Essa crítica estabelecida no próprio enunciado fílmico alinha-se, de certa forma, ao pensamento de Foucault em relação à etnologia - ciência que mantém laços tênues com a antropologia - no que diz respeito ao seu papel diante dos povos denominados "sem história":

Adivinha-se o prestígio e a importância de uma etnologia que, em vez de se definir primeiro, como o fez até aqui, pelo estudo das sociedades sem história, procurasse deliberadamente o seu objetivo no campo dos processos inconscientes que caracterizam o sistema de uma dada cultura; ela poria em jogo assim a relação de historicidade, constitutiva de toda a etnologia em geral, no interior da dimensão onde sempre se desenrolou a psicanálise. (Foucault, 1967: 91).

Trata-se de uma visão centrada em rever o posicionamento das ciências humanas e que procura, ao diagnosticar a etnologia, estabelecer certos parâmetros analíticos que possam verificar com maior acuidade os processos envolvidos em sua atividade. Se em Congo as emanações do inconsciente parecem afastar-se da trama verbal em jogo, nota-se, nas imagens icônicas e no encadeamento do som outras mediações que procuram atender à busca de uma história perdida, seja através de seus fantasmas, de seus mitos e de suas manifestações num presente vazio. Se há uma postura declarada que depõe contra um certo cientificismo, nota-se, neste mesmo percurso, a crise do sujeito que fala e expõe suas reminiscências como realizador imerso numa cultura urbana e letrada, haja visto as referências explícitas a Artur Ramos, Câmara Cascudo e Mário de Andrade, bem como a rede de influências que se deixam ecoar no próprio texto, a saber, Dziga Vertov e Joaquim Pedro de Andrade.

No campo sonoro promove-se a mesma descontinuidade presente no tecido das imagens; assim, desacordes da música contemporânea são alinhavados com batuques, ruídos e silêncio, nesse entremeio a voz over de uma criança lê um texto sobre a congada. Identificamos o ato da leitura pela dificuldade com que tenta, em vão, oferecer elementos do auto. Temos uma crítica às vo- 
zes empostadas, frequentemente exercidas por homens nos documentários, a voz que unifica, informa e educa, a voz de Deus, interessa mais essa postura enunciativa que o seu próprio conteúdo.

As mediações operadas no processo analógico transbordam em reminiscências, ruínas e um vazio inquietante. A imagem em primeiro plano do rosto de um jovem mulato habitante da zona rural, a fotografia de uma família de negros, o plano geral de uma casa grande quase abandonada e do que seria um engenho com crianças mulatas brincando traduzem o universo complexo do processo de miscigenação do povo brasileiro que caminhou ao lado de um processo de opressão e de abandono dessa população no meio rural.

A foto posada da família restitui essa dimensão conflitiva das tensões subjetivas e identitárias do negro, sufocadas pelo branco. Esse encadeamento tem como finalidade inserir no espaço em que seria praticada a congada uma interrogação sobre os processos de desagregação da cultura negra e sua luta pela sobrevivência num ambiente hostil. Em outro momento, a câmera percorre as paredes de uma sala burguesa e num giro de $360^{\circ}$ pára momentaneamente diante de medalhões com as seguintes inscrições "indústria", "poesia", "escultura", "pintura", "amor", "pátria", "música", "jurisprudência”, "glória”, "deus", "fidelidade", "agricultura", "medicina", novamente vemos tecer um jogo de oposição em que, de um lado, está o ambiente letrado, burguês e cristão de origem européia, de outro, a congada como movimento de resistência. Assim, como os letreiros que ao mesmo tempo informam de maneira inquiridora a congada, oferecem informações sem vínculo aparente, também vemos no material icônico uma oscilação entre um estado de descrença em relação ao ato de documentar atualizado pelas imagens prosaicas do feno e dos cachorros copulando, e um pronunciamento mordaz em relação aos processos de dissolução envolvidos, e isto se conclui pelas as imagens dos ex-votos e o plano final constituído de caveiras.

\section{Considerações finais}

Radical em sua estrutura, Congo constrói-se por uma montagem intelectual que prevê a participação e a reflexão do espectador. Em seu diálogo com suportes de naturezas diversas (palavra, foto, imagem filmada, fotograma em branco e em negro, gravura, sonoridades múltiplas), o filme transborda em questionamentos. Essa atitude reflexiva alinha-se, num certo sentido, ao pensamento de inspiração pós-estruturalista (Clifford, 1986, Trinh T. Minh-ha, 1993) que revê o posicionamento do sujeito centralizador do discurso e o papel do antropólogo por meio da reavaliação dos instrumentos tradicionalmente utilizados para a análise dos processos culturais, promovendo deslocamento da voz que 
outrora procurava nutrir-se de objetividade e cientificidade, ensejando um discurso híbrido, auto-reflexivo e consciente das malhas que esses instrumentos oferecem ao labor científico ou artístico.

Congo sinaliza uma postura radical no horizonte do documentário brasileiro. Sabe-se que no período em que foi realizado havia a preocupação emergente por parte de alguns cineastas em preservar, por meio de estratégias convencionais e também em diálogo com o cinema moderno, manifestações da cultura popular situadas na zona rural, onde o sertão é o emblema e a Caravana Farkas assinala a produção que atualiza tais propósitos, justamente num período marcado ideologicamente pela defesa de um imaginário da nação focado nas representações sobre o povo. Ao se posicionar pela negação desse tipo de registro, sobretudo aqueles mais convencionais, e realizar um filme afeito à denúncia dos métodos de composição, traduzindo por vozes variadas um fenômeno que se embrenha de forma complexa na estrutura social, Arthur Omar assume outra postura moderna (antecipação da pós-modernidade?) a do artista em crise com os métodos de representação e que mantém uma preocupação flagrante em situar seu produto desviando-se da defesa da identidade e assumindo as tensões que permanecem nos processos de formação, desenvolvimento e práticas da cultura brasileira.

\section{Referências bibliográficas}

Bernardet, J.-C. (1985). Cineastas e imagens do povo. São Paulo: Brasiliense.

Cabral, O.R. (1951). As danças de congos no sul do Brasil. Província de São Pedro, jun., 06(15): 102-105. Porto Alegrepp.

Câmara Cascudo, L. (1979). Cinco livros do povo. João Pessoa: Editora UFPB.

Clifford, J. (1986). Introduction: partial truths. In J. Clifford \& G. Marcus (Eds) Writing culture. The poetics and politcs of ethnography. Berkeley: University of California Press.

Foucault, M. (1967). As ciências humanas. In E.P. Coelho, Estruturalismo: Antologia de textos teóricos. Lisboa: Portugália.

Omar, A. (1997). Antropologia da face gloriosa. São Paulo: Cosac \& Naify.

Omar, A. (1997). O antidocumentário provisoriamente. Cinemais, novembro/dezembro, (08): 179-203. Rio de Janeiro.

Omar, A. (2001). A lógica do êxtase. Rio de Janeiro: Centro Cultural Banco do Brasil. 
Ramos, G. (s.d.). Arthur Omar: o anti-documentário em Congo (1972) e $O$ anno de 1798 (1975). São Paulo, 1993. Disponível em: http://www.muse uvirtual.com.br/targets/galleries/targets/mvab/targets/arthuromar/targets/ entrevistas/languages/portuguese/html/sobreoantidocumentario.html

Renov, M. (1986). Rethinking documentary: toward a taxonomy of mediation. Wide Angle, 18(3/4): 71-96. Birmingham.

Trinh, T. Minh-Ha (1990). Documentary is/not a name. October, Spring, 52: 76-98. Cambridge.

\section{Filmografia}

Congo (1972), de Arthur Omar.

A coroação de uma rainha (1993), de Arthur Omar.

A lógica do êxtase (1998), de Arthur Omar.

Pânico sutil (1998), de Arthur Omar.

Ressurreição (1989), de Arthur Omar.

Sumidades Carnavalescas (1971), de Arthur Omar.

Tesouro da juventude (1977), de Arthur Omar.

Triste trópico (1974), de Arthur Omar.

A última sereia (1997), de Arthur Omar. 